\title{
A 34ª RASBQ ENTRA PARA A HISTÓRIA DA SBQ NO ANO INTERNACIONAL DA QUÍMICA
}

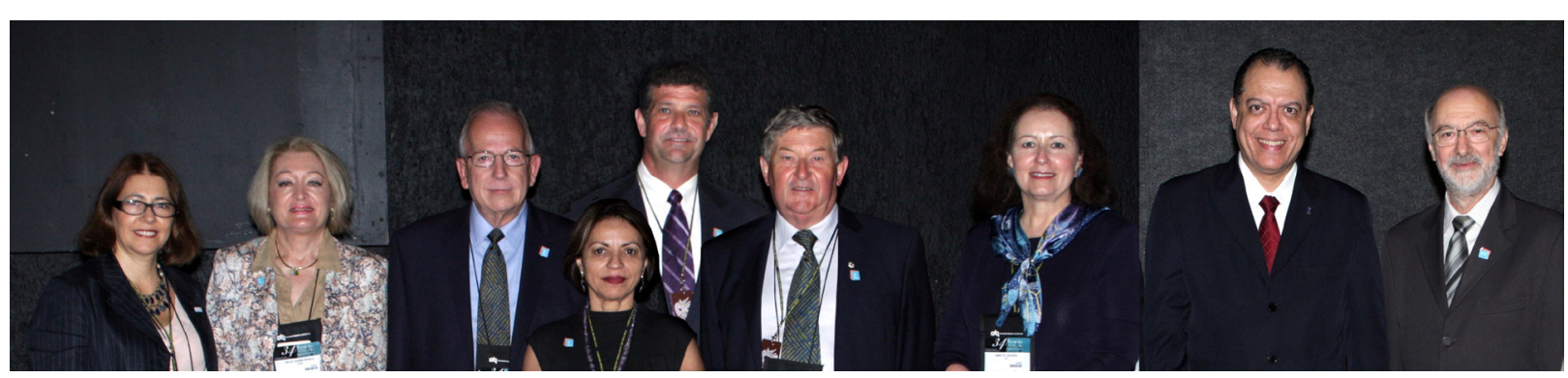

Da esq. para a dir: Alejandra Palermo, Nicole J. Moreau, Terry Renner, Vanderlan da S. Bolzani, Bradley Miller, David Phillips, Nancy B. Jackson,

Glaucius Oliva e César Zucco

Foi realizada, de 23 a 26 de maio em Florianópolis - SC, contando com mais de 4.500 inscritos, a maior Reunião Anual de nossa história e, sem dúvida, uma das mais bem sucedidas. Uma cidade linda, clima agradável, excelente infraestrutura e atividades científicas e sociais de alto nível marcaram a primeira passagem da RA pela região Sul.

A 34ª Reunião Anual da Sociedade Brasileira de Química (34 RASBQ), em comemoração ao Ano Internacional da Química (AIQ-2011), ofereceu uma programação bastante diversificada e dinâmica, tendo como tema central "Química para um mundo melhor". Foram realizados 12 workshops, 14 minicursos, 15 conferências convidadas, 2 conferências empresa, 2 simpósios, 4 sessões temáticas, 15 sessões coordenadas e 3 sessões de painéis, além de lançamentos de livros, feira de exposições, homenagens e divulgação das atividades da SBQ no AIQ-2011. Na parte social, tivemos três momentos marcantes de confraternização, uma festa na sessão de abertura em comemoração ao AIQ-2011, a tradicional festa da RA com a temática "Química na ilha da magia”, e um coquetel de encerramento. Houve também o lançamento da carteirinha de sócio da SBQ, uma conquista muito celebrada.

A sessão de abertura contou com grande público que lotou as dependências do auditório central Tuguá do centro de convenções do Costão do Santinho Resort, onde os jovens, que eram ampla maioria, foram estimulados pelo Presidente da SBQ, Prof. César Zucco, a assumir um compromisso através da Química para o desenvolvimento de um mundo melhor. O presidente do Conselho Nacional de Desenvolvimento Científico e Tecnológico (CNPq), Prof. Glaucius Oliva, enfatizou as contribuições da Química para os avanços em Ciência, Tecnologia e Inovação de nosso país, e comentou que o ensino superior e a pesquisa avançaram de forma consistente nas últimas décadas, elevando os indicadores do Brasil em termos internacionais. Na sequência, a Profa. Vanderlan da S. Bolzani explorou o fascinante universo micromolecular da biodiversidade, em sua brilhante conferência, através de exemplos de três famílias de plantas que ilustraram uma notável carreira científica. Essa sessão de abertura teve, pela primeira vez, transmissão ao vivo pela internet, alcançando milhares de pessoas em todo o Brasil e no mundo. Logo após o encerramento da RA, a Profa. Vanderlan foi escolhida pela IUPAC como uma das "IYC 2011 Distinguished Woman in Chemistry" e será homenageada em Porto Rico no "IUPAC 2011 World Chemistry Congress" em agosto próximo. Essa conquista é motivo de orgulho para a SBQ e demonstra o papel de destaque das cientistas brasileiras em um cenário internacional cada vez mais competitivo. Em consonância com este alto padrão de desempenho, as mulheres estiveram em evidência também na sessão especial "Mulheres na Química brasileira", realizada no dia 25, onde cinco pesquisadoras brasileiras foram homenageadas pelo sucesso profissional e participação efetiva em atividades da SBQ e do AIQ-2011. Foram elas, as Profas. Anita J. Marsaioli (UNICAMP), Dorila P. Veloso (UFMG),
Maria D. Vargas (UFF), Marília O. F. Goulart (UFAL) e Claudia M. de Rezende (UFRJ).

Os workshops, atividades promovidas pelas Divisões Científicas e que tradicionalmente antecedem a abertura oficial das RAs, foram capazes de atender à missão de aproximar e integrar alunos e professores de todas as partes do Brasil, através de discussões de temas de interesse comum aos associados. Neste ano, com a coordenação do Prof. Hugo. T. S. Braibante, um dos workshops foi dedicado exclusivamente às Secretarias Regionais, com a finalidade de reforçar o compromisso da SBQ com o desenvolvimento de atividades com maior equilíbrio e representatividade regional. Os minicursos, com características multi- e interdisciplinares, cumpriram seu objetivo de mapear vários cenários científicos e proporcionar novos desafios e oportunidades para alunos de graduação e pós-graduação. Quatorze temas apresentados por 19 especialistas de reconhecida experiência mantiveram cheias as salas do centro de convenções, durante 3 dias.

As conferências convidadas confirmaram seu papel fundamental na criação de ambientes favoráveis para a discussão do estado da arte da Química em áreas de extremo interesse como energia, educação, saúde humana, química verde, biodiversidade, entre outras. Os conferencistas, 8 do Brasil e 7 do exterior, atraíram um público muito participativo e interessado, permitindo debates, trocas de ideias e experiências. Entre as várias conferências que encheram de brilho os dias 24 e 26, destacam-se as participações da Presidente da Internation Union of Pure and Applied Chemistry (IUPAC), Profa. Nicole J. Moreau, que falou sobre o tema "Beyond 2011 - What can we as chemists do to keep the IYC alive?", e da Dra. Nancy B. Jackson, presidente da ACS, com sua conferência "Sunshine to petrol: solar thermal conversion of carbon dioxide to liquid fuels". As conferências empresa garantiram novamente um canal efetivo de comunicação e maior aproximação entre universidade e empresa.

Com palestrantes de grande renome e foco em assuntos atuais da Química e de suas interfaces multidisciplinares, as 4 sessões temáticas realizadas no dia 26 atraíram a atenção de plateias bastante diversificadas. Nelas foram abordados temas relevantes como: "fármacos e medicamentos" que, com a coordenação do Prof. Eliezer J. Barreiro (UFRJ) e participação dos Profs. Ronaldo A. Pilli (UNICAMP) e Adriano L. Monteiro (UFRGS), enfatizou a importância da interdisciplinaridade como ferramenta eficaz para aproximar a linguagem dos químicos nas interfaces entre as ciências farmacêuticas, biológicas e médicas; "materiais avançados para os desafios da sociedade atual" que, com coordenação da Profa. Glaura G. Silva (UFMG), reuniu principalmente membros das Divisões de Química dos Materiais, Físico-Química e Eletroquímica e Eletroanalítica para discussão do importante papel da integração entre as áreas para novos avanços tecnológicos; "novas tendências de métodos em RMN e EM" que, sob a coordenação dos Profs. Luiz Henrique Catalani (USP) e 
Norberto P. Lopes (FCFRP/USP), destacou como os crescentes avanços em instrumentação têm beneficiado pesquisadores de todas as áreas da ciência, refletindo intensamente na Química; "jovens talentos na ciência”, resultante de iniciativa conjunta da SBQ e ACS, essa sessão intitulada "The International Year of Chemistry 2011: Young Talents in Science" teve como objetivo valorizar cientistas do Brasil e dos Estados Unidos que alcançaram grande prestígio internacional, antes de completarem 40 anos. Com a coordenação da Profa. Vanderlan da S. Bolzani e do Dr. Bradley Miller, contando ainda com a participação especial dos Presidentes da SBQ e ACS, apresentaram suas miniconferências e foram homenageados com troféus e certificados os Profs. Xi Chen, University of California, Davis ("Carbohydrates and influenza"), Michelle Chang, University of California, Berkeley ("Engineering E. coli for new chemical function"), Mohammad Movassaghi, Massachusetts Institute of Technology, ("Complex molecule total synthesis"), Adriano D. Andricopulo - USP ("Integration of structure- and ligand-based approaches in medicinal chemistry and drug design"), Pierre M. Esteves - UFRJ ("Carbocations and chemistry of electrophiles: new insights and paradigms") e Paulo A. Z. Suarez - UnB ("Biodiesel preparation and modification in multi-phase catalytic systems").

Os dois simpósios do dia 25 tiveram amplo impacto na comunidade química, devido aos assuntos abordados e à excelente equipe de palestrantes e debatedores. No simpósio "Avançando na avaliação científica em Química”, coordenado pelo Presidente da SBQ e com as participações do Presidente do CNPq e dos Profs. Jailson B. de Andrade (UFBA) e Ademir Neves (UFSC), foram discutidos, entre outros, o momento atual da comunidade científica brasileira, o papel da interdisciplinaridade, a aproximação da universidade com o setor produtivo, o perfil de crescimento da ciência e tecnologia no Brasil, a evolução dos modelos de avaliação e a necessidade de aperfeiçoamento dos indicadores de produtividade científica. No simpósio "Integrated solutions for tomorrow's world, the role of the scientific societies", coordenado pela Profa. Vanderlan da S. Bolzani, responsável pelos assuntos internacionais da SBQ, e pela Dra. Alejandra Palermo, coordenadora de projetos internacionais da Royal Society of Chemistry (RSC), e que contou com a presença de Profa. Nicole J. Moreau, Presidente da IUPAC, Dr. Terry Renner, diretor executivo da IUPAC, Prof. David Phillips, Presidente da RSC, Dra. Nancy B. Jackson, Presidente da ACS, e Prof. Martyn Poliakoff, Universidade de Nottingham, foi discutida a participação das sociedades científicas que, com sua estrutura e capilaridade, conseguem chegar a um grande número de pessoas, em vários países, como promovedoras de ações relevantes como, por exemplo, o AIQ-2011. No mundo todo, as atividades do AIQ-2011 compõem uma rede de inúmeras iniciativas que incluem a realização de eventos especiais de divulgação científica e difusão do conhecimento em todos os níveis, a edição e publicação de livros e textos especializados, a realização de exposições itinerantes e outras atividades educativas e culturais em universidades e escolas de ensino fundamental e médio, além de vários outros projetos como o "365 dias de Química”, que conta todos os dias com uma nova entrevista e a apresentação de uma nova molécula. A SBQ, junto com outros órgãos representativos da Química brasileira, tem se envolvido intensamente no planejamento, divulgação e execução de ações capazes de congregar a comunidade científica brasileira. As realizações do AIQ no Brasil, coordenadas pela Profa. Claudia M. de Rezende (UFRJ), podem ser acessadas em http:// www.quimica2011.org.br.

O sucesso alcançado em sua RA e nas atividades do AIQ-2011 torna o momento adequado para uma reflexão em dois aspectos fundamentais: a crescente inserção da SBQ e da Química brasileira no cenário internacional e, a participação dos jovens na ciência nacional. No primeiro caso, é notável o resultado das várias ações que têm colocado a SBQ, em especial a Química brasileira, em evidência no mundo todo. Prova disso é o destaque recebido pela SBQ em julho pp. na Chemical \& Engineering News (4/7/11 - C\&EN, vol. 89, $\mathrm{n}^{\circ}$ 27, p. 74), da ACS, em uma matéria intitulada "Brazil Attracts a Crowd of Chemists" ("Brasil atrai uma multidão de químicos"), que pode ser lida em sua versão completa em http://pubs.acs.org/cen/ meetings/89/8927meetings.html. A matéria valoriza a 34 ${ }^{\mathrm{a}} \mathrm{RASBQ}$, com elogios para as atividades de abrangência internacional, realizadas com muito êxito, reunindo sociedades científicas do mundo todo, e com destaque para a marcante e entusiasmada participação dos jovens, bem como das mulheres, que foram maioria. Outro fato extremamente importante que demonstra a inserção internacional da SBQ e nos enche de alegria e orgulho, é termos contado com a presença dos Presidentes da IUPAC, ACS e RSC, além do Presidente do CNPq e do Diretor Científico da FAPERJ, Prof. Jerson L. Silva, entre outras autoridades do cenário científico nacional e internacional.

Para continuar a nossa caminhada de forma construtiva, é preciso valorizar estas oportunidades de crescimento e olhar para o futuro, com foco em desafios cada vez maiores e enriquecedores em prol de nossa Sociedade. Como lembrado por nosso Presidente, temos o compromisso não somente de continuar com as atividades do AIQ2011, mas de estender esta projeção de desenvolvimento para o futuro, vislumbrando patamares mais elevados. Um dos grandes desafios da atual gestão, aproveitando esse momento favorável, é trabalhar fortemente para que o Brasil possa sediar a Reunião Internacional da IUPAC em 2017, na comemoração dos 40 anos da SBQ.

No outro aspecto fundamental, a participação dos jovens, amplamente destacada por todos os Presidentes de sociedades e entidades presentes, deve ser continuamente estimulada. Apesar de sua importância inquestionável para o futuro do país em vários planos e ambientes, é necessário ampliar as oportunidades aos jovens. Embora possuidor de vasta fonte de recursos humanos, com cientistas jovens de excelente formação, alta competência e reconhecido talento, existe, de fato, uma grande diferença entre o tradicional discurso e as oportunidades efetivas que têm sido criadas. O desafio de transformar essa perspectiva em realidade requer ações inteligentes e planejadas apropriadamente, capazes de garantir uma inserção segura e saudável em vários setores, para que jovens talentos possam brilhar em cenários mais relevantes da ciência e tecnologia nacionais. Os mais velhos, com sua vasta experiência e visão de futuro, devem estar atentos e olhar com mais cuidado e generosidade para os jovens, pois é preciso transformar o discurso bonito em prática. De forma semelhante, é necessária uma maior valorização das mulheres na ciência brasileira, para que possam alcançar uma representatividade compatível com o elevado nível alcançado.

A SBQ demonstrou mais uma vez a sua grandeza e força na realização da $34^{\mathrm{a}} \mathrm{RASBQ}$. É indispensável agradecer a dedicação e o esforço de muitas pessoas que foram essenciais para a organização dessa Reunião. Em especial, aos meus colegas das Comissões Organizadora, Científica e Organizadora Local. Também aos meus colegas de Diretoria e Conselho da SBQ e a todos os membros de nossa secretaria nacional, sem a qual não seria possível atingir esse nível de excelência em nossas realizações. A SBQ agradece imensamente o apoio do CNPq, da CAPES, da FAPESC, da FAPESP, da FAPEMIG, do Departamento de Química da UFSC, da Natura e da Petrobras.

Para fechar com chave de ouro nossa RA, preparamos um Boletim Eletrônico Especial, em formato de Revista Eletrônica, trazendo um panorama geral da 34 ${ }^{\text {a }}$ RASBQ (http://boletim.sbq.org.br/ beespecialdestaque34ra.php).

Por fim, saudamos e agradecemos a todos que contribuíram e tornaram possível a construção deste capítulo tão significativo de nossa história. Em maio de 2012, estaremos novamente juntos na 35 RASBQ.

Obrigado e até a próxima! 